\title{
The importance of testing method to evaluate the most representative mode I fracture toughness value of brittle rocks
}

\begin{abstract}
One of the most fundamental parameters in rock mechanics is critical fracture toughness $\left(\mathrm{K}_{\mathrm{IC}}\right)$, which describes the resistance of rock material to crack propagation. $\mathrm{K}_{\mathrm{IC}}$ is an important material property, which corresponds to the critical state of the stress intensity factor required for crack initiation and subsequent propagation. Therefore, assessment of resistance to crack propagation is crucial for understanding the behavior of structures involving brittle materials. To determine fracture toughness values of rocks, the International Society of Rock Mechanics (ISRM) suggests three methods: Short Rod (SR) specimen tests, Chevron Bend (CB) specimen tests and Cracked Chevron Notch Brazilian Disc (CCNBD) tests. In order to determine the mode I fracture toughness of tuff specimens, SR and CCNBD, were used in this study. It was found that CCNBD has more advantages over the SR method in terms of sample preparation and failure load consistency. The obtained fracture toughness values are different because of different dimensionless stress intensity factor values. The fracture toughness values obtained by the SR method were higher compared with the fracture values obtained by the CCNBD method. The obtained $\mathrm{K}_{\mathrm{IC}}$ results were compared by using some well-known relationships between fracture toughness and rock physical properties to confirm the validity of those results.
\end{abstract}

Keywords: fracture toughness of rocks, short rod test, CCNBD test, Rock fracture, crack coalescence, crack initiation, rock boring equipment, rock bursting, rock drilling forces, wellbore stability, geometric parameters, hard rock types, dimension notations, tuff SR specimens, self-pre crack
Volume 4 Issue 5 - 2018

\author{
Nazife Erarslan \\ Department of mining and mineral process engineering,Adana \\ Science and Technology University, Turkey
}

\author{
Correspondence: Nazife Erarslan, Department of mining and \\ mineral process engineering, Adana Science and Technology \\ University, Turkey, Tel +90 455000020 94, \\ Emailnerarslan@adanabtu.edu.tr
}

Received: July 25, 2018 | Published: December 31, 2018

\section{Introduction}

Rock materials are discontinuous at all scales. At the micro scale, defects causing stress concentrations include micro cracks, grain boundaries, pores and bedding planes, while at the macro scale geologic fractures are referred to as joints (opening) or faults (shearing), based on their genesis. Numerous experimental and theoretical efforts have been devoted to the understanding of crack initiation, propagation, and coalescence in brittle materials. Under tension, these three processes take place almost simultaneously in brittle rocks. However, the failure process is more complex under compression. Under both kinds of loading, rupture (failure) of the material results primarily from stable and unstable fracture propagation and crack coalescence, rather than directly from fracture initiation. Rock fracture toughness is a key parameter in rock fracture mechanics used to determine crack initiation and propagation, which is important in the design of rock boring equipment, tunneling, rock cutting, rock bursting, and determination of rock drilling forces, wellbore stability and stability of jointed rock masses. As a result, it is important to test rock fracture toughness with adequate accuracy. To assess fracture toughness values of brittle materials like rocks, the ISRM suggests three methods: Short Rod (SR) specimen ${ }^{1}$, Chevron Bend (CB) specimen ${ }^{1}$ and Cracked Chevron Notch Brazilian Disc (CCNBD) specimen².

Comparisons between ISRM suggested methods have been mostly focused on $\mathrm{SR}$ and $\mathrm{CB}$ specimens ${ }^{3}$, or on $\mathrm{CCNBD}$ and $\mathrm{CB}$ specimens ${ }^{4}$. Although some consistency has been provided by these suggested methods, a variation of $20-30 \%$ was still obtained for the same rock type. Recent research has indicated that CCNBD values are markedly smaller than other comparable tests ${ }^{3,5,6}$. However, the consistency of tested mode I fracture toughness between CCNBD and SR specimens has not been validated adequately and needs to be compared after performing more experiments. The geometry of a CCNBD specimen is illustrated in Figure 1. The chevron notch causes crack propagation to start at the tip of the $\mathrm{V}$ alignment and to proceed radically outwards in a stable fashion until the point where the fracture toughness is calculated.

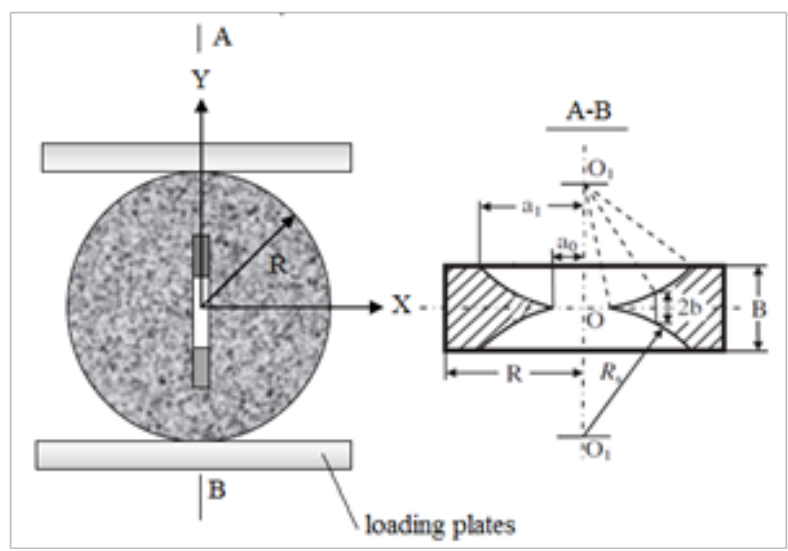

Figure I The CCNBD specimen geometry with a recommended test fixture

All dimensions of the geometry should be converted into dimensionless parameters with respect to the specimen radius, $R$, and diameter, $D$. The suggested standard specimen dimensions are given in the ISRM suggested methods. ${ }^{7}$ Other selections of specimen geometrical dimensions are possible, but in order to have a valid test, 
the two most important selected dimensions; dimensionless final notched crack length $\left(\alpha_{1}\right)$ and the dimensionless quantity, $\alpha_{\mathrm{B}}$, must fall within the range outlined in Figure 2. The length of initial crack $\left(\alpha_{0}\right)$, final notched crack $\left(\alpha_{1}\right)$ and $\alpha_{\mathrm{B}}(B / R)$ are the three geometric parameters for the CCNBD specimens. ${ }^{7}$ All specimen geometries used in this research were in the valid ranges indicated by the red circle in Figure 2; the full validity range is also shown. For fracture toughness testing, the important stress intensity factor value for the specimen is the minimum stress intensity factor, denoted as $Y_{\min }^{*}$, as it corresponds to the failure load $\left(P_{\max }\right)$ recorded during testing. The fracture toughness value of a CCNBD specimen is calculated as follows:

$$
K_{C}=\frac{P_{\max }}{B \sqrt{R}} Y_{\min }^{*}
$$

where $P_{\max }$ is the maximum failure load in N, B is the thickness in $\mathrm{mm}, R$ is the radius of the CCNBD specimen in $\mathrm{mm}$, and $Y_{\min }^{*}$ is the critical dimensionless stress intensity factor. For CCNBD specimens within the valid range shown in Figure 5, Figure 2, the critical dimensionless stress intensity value $Y_{\min }^{*}$, which is determined by the specimen geometry dimensions $\alpha_{0}\left(a_{0}\right), \alpha_{1}\left(a_{1}\right)$ and $\alpha_{\mathrm{B}}(B)$ only, can be calculated as given by the ISRM: ${ }^{7} Y_{\min }^{*}=u \cdot e^{v \cdot{ }^{\circ} 1}$ where constants $u$ and $v$ are listed in the ISRM suggested methods. ${ }^{7} \mathrm{SR}$ method is used to evaluate mode I fracture toughness values only. The SR method was introduced by Barker ${ }^{8}$ and it became an ISRM-suggested method after the studies by Ouchterlony. ${ }^{1}$ The specimen is a typical core-based one with a machined notch along the rod axis. The external load is applied to the notch mouth to split the specimen into two identical halves. As tensile loading is applied perpendicular to the plane of the notch, this may result in failures at the specimen and loading equipment contacts, especially for hard rock types. Figure 3 shows schematically the specimen configuration and the loading and dimension notations. The specimen geometry is restricted in dimensions as listed in Figure 3.

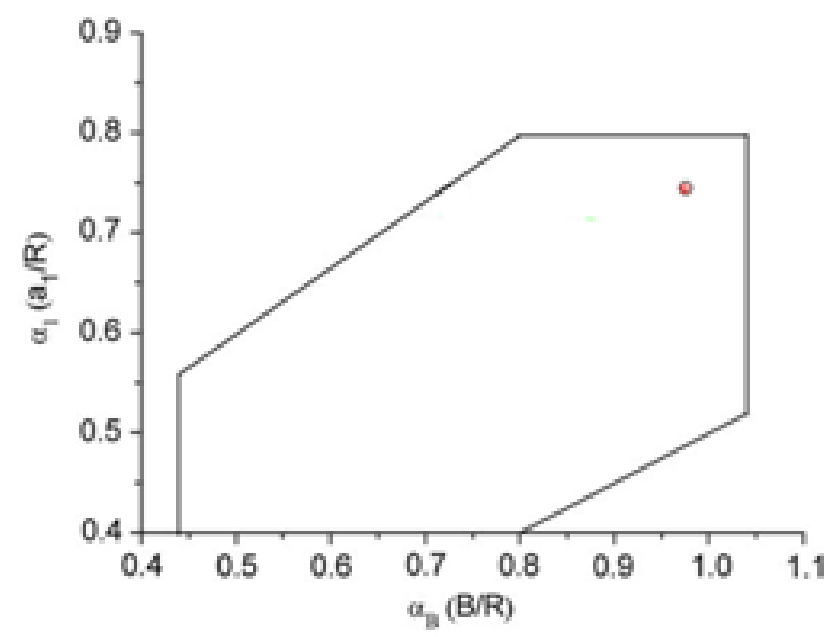

Figure 2 Valid geometrical ranges of CCNBD specimens for fracture toughness testing

The SR test has two levels. Level I testing require only the recording of the peak load, which is used to evaluate the level I fracture toughness. This test should be performed under load control with an average stress intensity factor rate $K_{S R}$ of more than or equal to $0.25 \mathrm{MPa} \sqrt{\mathrm{m}} / \mathrm{s}$.. Level II testing requires the recording of the complete load versus the CMOD (Crack Mouth Opening Displacement) curve. The level II fracture toughness, which accounts for the effect of nonlinearity, is determined to depend on whether the two unloading lines span the evaluation point. ${ }^{9}$ This test should be performed in displacement control with a CMOD rate faster than $0.017 K_{S R} /(E \sqrt{D}) \mathrm{m} / \mathrm{s} . K_{S R}$ is the level I fracture toughness, $E$ is Young's modulus and $D$ is the diameter of the specimen. The fracture toughness calculation is achieved by considering the following equation, which was proposed by ${ }^{1}$ for Level I testing:

$$
K_{S R}=C_{K} 24.0 P_{\max } / D^{1.5}
$$

Where KSR is fracture toughness $(\mathrm{MPa} \sqrt{\mathrm{m}}), P_{\max }$ is failure load (MN), $D$ is the specimen diameter $(\mathrm{m})$, and $C_{K}$ is the correction factor to account for the size variation of the specimen, given by

$$
C_{K}=1-\frac{0.6 \Delta W}{D}+\frac{1.4 \Delta \alpha_{0}}{D}-0.01 \Delta \theta
$$

Where $\Delta W$ is variation in specimen height $W(\mathrm{~m}), \Delta a_{0}$ is the initial position of the chevron notch apex $(\mathrm{m})$ and $\theta$ is the chevron notch angle (in radians). What is important in both tests is to determine where the crack will start. Then, the fracture toughness will be the value of the crack where the transition point from the stable crack to unstable crack after the crack initiation site is determined.

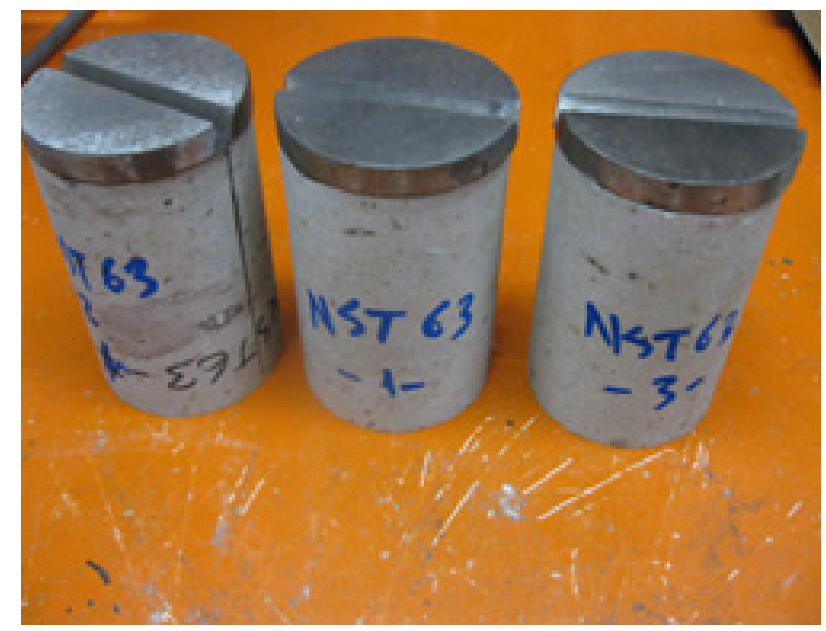

Figure 3 Tuff SR specimens before testing

\section{Methods}

The tests were carried out on tuff specimens. A circular $40 \mathrm{~mm}$ diamond saw was used to cut the required notch Figure 5. A precisely designed jig was used to ensure that the chevron notches are exactly in the center of thedisc. Additionally, the jig was controlled by an electronic alignment device with displacement calculated on $\mathrm{x}, \mathrm{y}$, $\mathrm{z}$ coordinates for accuracy in controlling the center alignment and penetration of the saw Figure 4. The thickness, $t$, of the notches was $1.4 \mathrm{~mm}$ and the thickness of the sample, $B$, was $25 \mathrm{~mm}$. The initial chevron notch crack length, $a_{0}$, was $7.5-8 \mathrm{~mm}$ and the final chevron notch crack length was $36-37 \mathrm{~mm}$. An Instron 6027 with $100 \mathrm{kN}$ load cell hydraulic servo-control testing system with Blue hill software 
was used to conduct the tests. Diametral displacement parallel to the loading direction was measured by means of an extensometer with 50 $\mathrm{mm}$ gauge length. The crack displacement was measured as CMOD across the crack mouth. The opening of the notch was measured by a clip gauge by attaching special knives. Instron 2670 model crack opening displacement gauge was used to measure CMOD values.
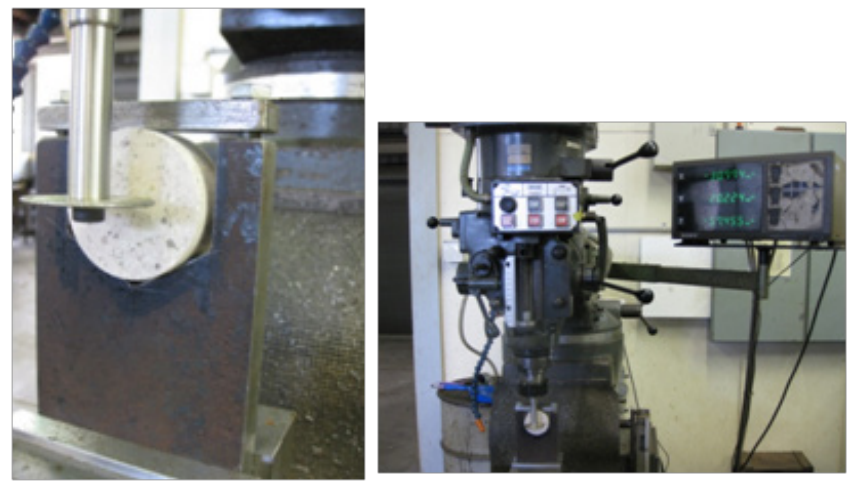

Figure 4 CCNBD specimen preparation equipment

Six CCNBD samples were tested under load control test conditions. The specimens were placed under the platens with zero crack inclination angle $\left(\theta=0^{\circ}\right)$ to provide mode I loading conditions. The loading rate was chosen as $9 \mathrm{kN} / \mathrm{s}$ to cause failure within $20 \mathrm{~s}$ as suggested by ISRM ${ }^{7}$. The load and CMOD readings were recorded continuously until failure. The tuff SR specimens' diameter and length were $52 \mathrm{~mm}$ and $75 \mathrm{~mm}$ respectively. The chevron angle, $\theta$, was $55^{\circ}$, and the chevron tip position was at $25 \mathrm{~mm}$. Figure 5 shows the SR samples before testing. The end plates were mounted parallel to and equidistant from the notch center plane. Each specimen was placed in the testing machine in such a way that the load transfer system was properly aligned. A small bias load was used to secure it in the correct position. Level I presume that the test will be run under load control. The load was recorded and the test was run until the specimen failed. The average stress intensity rate during the test was $0.25 \mathrm{MPa} \sqrt{\mathrm{m}} / \mathrm{sec}$ so that failure occurs within 10s of initial load application. Eight SR samples were tested and results are given in the following sections.

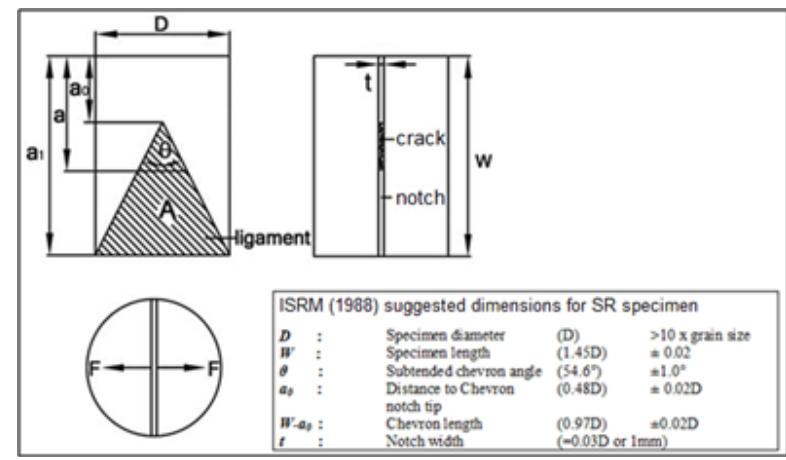

Figure 5 Short Rod specimen and associated notations

\section{Results}

In general, a load to achieve opening mode crack propagation can be applied to the specimen by direct tension, compression or bending. These two SR and CCNBD methods could be classified in terms of their loading conditions. The SR method is one of the methods suggested by ISRM ${ }^{10}$ in which a tensile load is directly applied perpendicular to the initial notch plane. In contrast, a CCNBD specimen is loaded in compression along the diametric plane. Hence, a comparison of these two methods has attracted attention in recent researches. Failure load and fracture toughness values of the tuff specimens determined with the CCNBD method were compared to the results of SR tests. The maximum failure loads for CCNBD specimens were found higher than those for SR specimens in general. Figure 6 shows the SR and CCNBD specimens after testing. The maximum recorded load and the calculated fracture toughness values obtained from both ISRM standard tests are shown in Table 1 mode I fracture toughness values of tuff specimens obtained for the CCNBD specimens are lower than those obtained by the SR method although bigger failure loads were obtained with CCNBD tests than with SR tests.

Table I Mode I fracture toughness values of tuff specimens obtained by SR and CCNBD tests

\begin{tabular}{lllll}
\hline Rock type & $\begin{array}{l}\boldsymbol{P}_{\max }(\mathbf{k N}) \\
\mathbf{S R}\end{array}$ & $\begin{array}{l}\boldsymbol{K}_{\text {Ic }}(\mathbf{S R}) \\
(\mathbf{M P a} \sqrt{\mathbf{m}})\end{array}$ & $\begin{array}{l}\boldsymbol{P}_{\max }(\mathbf{k N}) \\
\mathbf{C C N B D}\end{array}$ & $\begin{array}{l}\boldsymbol{K}_{\text {Ir }}(\mathbf{C C N B D}) \\
(\mathbf{M P a} \sqrt{\mathbf{m}})\end{array}$ \\
\hline Tuff-I & 1.0 & 2.02 & 5.25 & 1.38 \\
Tuff-I & 0.99 & 2.01 & 5.1 & 1.34 \\
Tuff-I & 1.3 & 2.63 & 6.18 & 1.63 \\
Tuff-I & 0.85 & 1.72 & 5.87 & 1.55 \\
Average & 1.03 & 2.1 & 5.6 & 1.48 \\
Tuff-2 & 1.10 & 2.23 & 4.68 & 1.21 \\
Tuff-2 & 1.07 & 2.18 & 6.47 & 1.68 \\
Tuff-2 & 1.12 & 2.26 & 6.35 & 1.64 \\
Tuff-2 & 1.05 & 2.12 & 7.10 & 1.83 \\
\hline Average & 1.08 & 2.19 & 6.15 & 1.59 \\
\hline
\end{tabular}
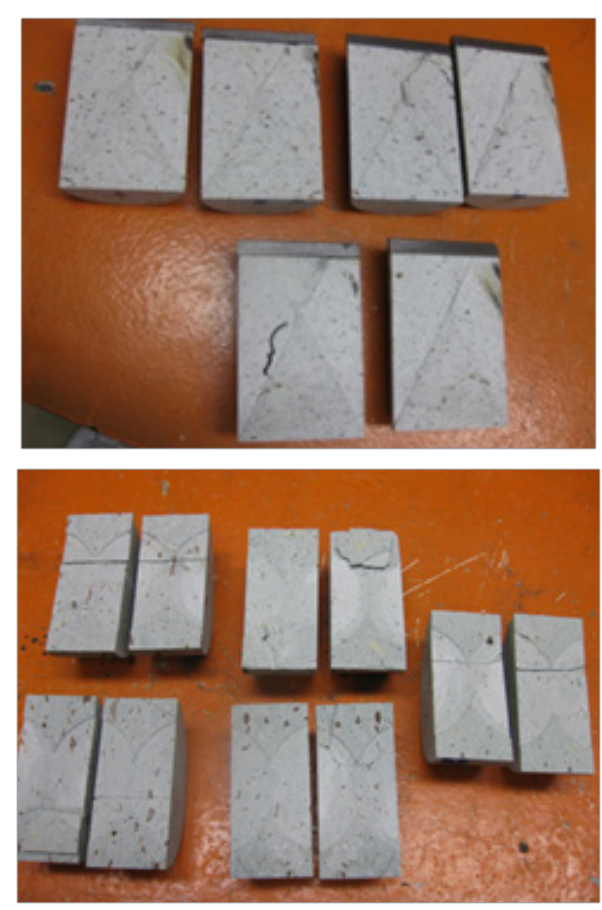

Figure 6 (a) SR and (b) CCNBD specimens after testing 


\section{Discussion}

The fracture toughness values obtained by the SR method are higher compared with the fracture values obtained by the CCNBD method. This research determined the critical stress intensity factor values $Y_{\min }^{*}$ of CCNBD specimens, the value of which is a crucial factor in the suggested method proposed by $\operatorname{ISRM}^{10}$ for mode I fracture toughness determination..$^{5}$ questioned the value of that key factor, stress intensity factor, for CCNBD specimens. The minimum stress intensity factor of CCNBD specimens was tried to be calibrated by ${ }^{5}$ It was concluded that the $Y_{\min }^{*}$ value calculated using the formula given by $\operatorname{ISRM}^{7}$ is too small compared with their calibrated value ${ }^{6}$. The obtained results in this research confirm ${ }^{5,6}$ findings. The $Y_{\min }^{*}$ value is found 0.98 using The ISRM $^{7}$ suggested formula and the calculated fracture toughness of tuff to be $1.48 \mathrm{MPa} \sqrt{\mathrm{m}}$. In contrast, the $Y_{\min }^{*}$ value to be 1.21 using the STCA method ${ }^{9}$ and the relevant fracture toughness value of the tuff to be $1.74 \mathrm{MPa} \sqrt{\mathrm{m}}$.

In contrast, the fracture toughness values obtained by the SR method have been found to be overestimated when compared with the fracture toughness of rocks found with CCNBD within the same ranges of uniaxial compressive strength (120-140 MPa) and uniaxial tensile strength $(12-14 \mathrm{MPa})^{11-13}$. In order to check the validity of fracture toughness values obtained by CCNBD, the relationship between fracture toughness and the physic-mechanical properties of rocks has been considered. One might expect that the mode I fracture toughness, in which the rock is separated by a tensile stress, would be related to the tensile strength of the rock. ${ }^{12}$ the mode I fracture toughness of rock is directly proportional to its tensile strength. As given by ${ }^{8}$ equation for the direct relation between uniaxial tensile strength and fracture toughness of rocks, the expected fracture toughness of tuff should be between 1.12-2 MPa $\sqrt{\mathrm{m}}$. The fracture toughness obtained from the CCNBD specimens is within this range; in contrast, the fracture toughness values obtained with the SR specimens are out of this range. Similar findings were made by ${ }^{12}$ for the relationship between fracture toughness and tensile strength of rocks. According to the equation ${ }^{12}$ the expected fracture toughness of e tuff should be between $1.5-1.9 \mathrm{MPa} \sqrt{\mathrm{m}}$. Further, there is a close correlation of mode I fracture toughness with uni axial compressive strength. ${ }^{12}$ According to the derived equation, the expected fracture toughness should be $1.58 \mathrm{MPa} \sqrt{\mathrm{m}}$ for tuff- 1 and $1.78 \mathrm{MPa} \sqrt{\mathrm{m}}$ for tuff- 2 . When a general comparison between the two methods is concerned, the CCNBD method had advantages in terms of easy sample preparation and less material required for testing. It is also unnecessary to perform pre-cracking for a CCNBD test specimen because it uses a chevron notch that self-pre crack during testing and leads to stable crack propagation. Another remarkable advantage of the CCNBD method over the SR method in terms of precision is higher load capacity and consistent results for each test. In our research, all the CCNBD samples show high precision in maximum load measurements. In addition, it is possible to measure mode I, mode II and mixed-mode I-II maximum SIF values by inclining the notch at different angles with respect to the axis of the diametric load..$^{14}$

According to the rock fracture mechanics, the stress intensity factor $\left(K_{I}\right)$ decreases with increasing crack length under a constant applied load and then a sharp crack initiates at the tip of the chevron notch, requiring an increasing load to grow stably at $K_{I}=K_{I C}$ to the notch base. After that propagated crack, unstable crack propagation starts because further growth would not require an increasing load.
Thus, fracture toughness $\left(K_{I C}\right)$ is calculated as that recorded ultimate load and the start of unstable crack propagation. According to the ${ }^{1}$ the critical crack length $a$ is between the initial chevron notch crack length, $a_{0}$, and the final chevron notch crack length, $a_{1}$. An analysis was done to obtain critical crack length in front of the chevron tip using the Straight-Through Crack Assumption (STCA) approach ${ }^{9}$. Figure 7 shows the normalized stress intensity factor versus normalized crack length for both CSTBD and CCNBD geometries. ${ }^{5,6}$ assumed that the critical crack length is between the initial chevron crack length and final chevron notch crack length. According to ${ }^{1}$, the critical crack length $a$ is between the initial chevron notch crack length, $\mathrm{a}_{0}$, and the final chevron notch crack length, $a_{1}$. As shown in Figure 7, unstable crack propagation starts at the dimensionless crack length where the dimensionless stress intensity factor is a minimum $Y_{\min }^{*}$ which equals to 1.21 , and the relevant fracture toughness value of the Brisbane tuff is $1.74 \mathrm{MPa} \sqrt{\mathrm{m}}$ where the critical crack length is equal to $13 \mathrm{~mm}(\alpha=0.5)$. This critical crack length indicates that unstable crack propagation starts between the initial chevron notch crack and final chevron notch crack lengths. It should be pointed out that the value of $Y_{\min }^{*}=0.87$ obtained using the formula ${ }^{7}$ is too small when it is compared with the corresponding value of $Y_{\min }^{*}=1.21$ obtained by STCA method. The obtained fracture toughness values are different because of different dimensionless stress intensity factor values.

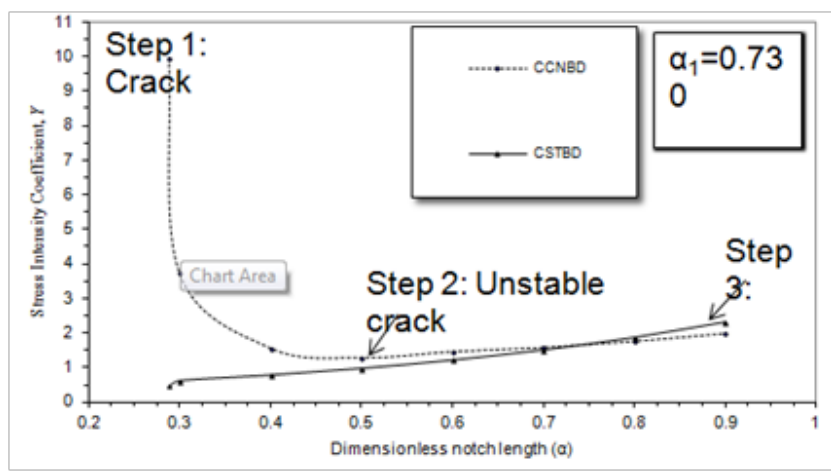

Figure 7 Dimensionless stress intensity factors for CSTBD and CCNBD specimens

\section{Conclusion}

In order to determine the mode I fracture toughness of tuff specimens, two ISRM suggested methods, SR and CCNBD, were used. It was found that CCNBD has more advantages over the SR method in terms of sample preparation and failure load consistency. The obtained fracture toughness values are different because of different dimensionless stress intensity factor values. The fracture toughness values obtained by the SR method were higher compared with the fracture values obtained by the CCNBD method. To confirm the validity of those methods, the results were compared with some relationships between fracture toughness and rock physical properties. Also, an analytical analysis was done to find the most accurate dimensionless stress intensity factor to calculate the fracture toughness of tuff specimens. The fracture toughness of tuff specimens obtained from the CCNBD specimens was found more precise compared with the results obtained from the SR method.

\section{Acknowledgments}

None. 


\section{Conflict of interests}

Authors declare that there is no conflict of interest

\section{References}

1. Ouchterlony F. Suggested methods for determining the fracture toughness of rock. Int J Rock Mech Min Sci Geomech Abs. 1988;25(2):71-96.

2. Fowell, RJ, Xu C, Dowd P. An Update on the Fracture Toughness Testing Methods Related to the Cracked Chevron-notched Brazilian Disk (CCNBD) Specimen. Pure Appl Geophys. 2006;16(5-6)3:1047-1057.

3. Cui Z, Liu D, An G, et al. A comparison of two ISRM suggested chevron notched specimens for testing mode-I rock fracture toughness. Int $J$ Rock Mech Min Sci. 2009;47( 5):871-876.

4. Iqbal MJ, Mohanty B. Experimental calibration of stress intensity factors of the ISRM suggested cracked chevron-notched Brazilian disc specimen used for determination of mode-I fracture toughness. Int J Rock Mech Min Sci. 2006;43(8):1270-1276.

5. Wang QZ, Jia XM, Kou SQ, et al. More accurate stress intensity factor derived by FEM analysis for the ISRM suggested rock fracture toughness specimen-CCNBD. Int J Rock Mech Min Sci. 2003;40:233-241.

6. Wang QZ, Jia M, Kou SQ, et al. The flattened Brazilian disc specimen used for testing elastic modulus, tensile strength and fracture toughness of brittle rocks: analytical and numerical results Int J Rock Mech Min Sci. 2004;41:245-253.
7. Fowell RJ. Suggested method for determining mode I fracture toughness using cracked chevron notched Brazilian disk (CCNBD) specimens. Int $J$ Rock Mech Min Sci Geomech Abs. 1995;32(1):57-64.

8. Barker LM. A simplified method for measuring plane strain fracture toughness. Eng Fract Mech. 1977;9(2):365-369.

9. Shetty DK, Rosenfield AR, Duckworth WH. Fracture toughness of ceramics measured by a chevron notch diametral compression test. $J \mathrm{Am}$ Ceram Soc. 1985;68(12):C325-C327.

10. ISRM. The complete ISRM suggested methods for rock characterization, testing, and monitoring: 1974-2006. Ulusay R, Hudson JA, editors. Suggested methods prepared by the Commission on Testing Methods Compilation arranged by the ISRM Turkish National Group, Ankara: Kozan Ofset; 2007.

11. Guo H, Aziz NI, Schmidt LC. Rock fracture toughness determination by the Brazilian test. Eng Geol. 1993; 33:177-188

12. Whittaker BN, Singh RN, Sun G. Rock Fracture Mechanics-Principles, Design and Applications. Elsevier.1992.

13. Zhang ZX. An imperical relation between mode I fracture toughness and tensile strength of rocks. Int J Rock Mech Min Sci.2002;39: 401-406.

14. Fowell RJ, Xu C. The cracked chevron notched Brazilian disk testgeometrical considerations for practical rock fracture toughness measurement. Preprint Proc. 34th U.S. Rock Mech Symp. 1993;30(7):657-660. 